\title{
EXPLORING UNIVERSITY STUDENTS PERCEPTION OF STRESS AND STRESS MANAGEMENT DURING A UNIVERSITY HEALTH PROMOTION DAY
}

\author{
FATHIA MOUSSE, HANA MORRISSEY, PATRICK ANTHONY BALL
}

\author{
School of Pharmacy, Faculty of Science and Engineering, University of Wolverhampton, United Kingdom
}

Email: hana.morrissey@wlv.ac.uk

Received: 18 May 2019, Revised and Accepted: 15 Jul 2019

\begin{abstract}
Objective: Stress, depression and anxiety are common, estimated at $19.7 \%$ people showing symptoms of these diseases. Although, effective treatment for depression and anxiety is available, they are still under diagnosed and treated to avoid stigma.

The study aims to explore the impact of pharmacist-led health promotion to increase the university local population awareness about stress, the causes and management.
\end{abstract}

Methods: A questionnaire-based study which included 50 participants aged 18 and over from the University of Wolverhampton.

Results: The findings revealed that stress has an impact on the individuals' lives, but they understood the effects of stress. The results informed the different factors that cause stress amongst the participants of multiple demographics.

Conclusion: Change is required to improve the mental well-being of the public. This study improved the University of Wolverhampton's student's knowledge and awareness of mental health. It provides in-depth knowledge for a future pharmacist to learn about stress management to help patients with more advanced services given in community pharmacies. Expanding knowledge within this area could assist millions of affected people to seek help.

Keywords: Stress, Self-Care, Mental Health, Mental Illness

(C) 2019 The Authors. Published by Innovare Academic Sciences Pvt Ltd. This is an open access article under the CC BY license (http://creativecommons.org/licenses/by/4.0/) DOI: http://dx.doi.org/10.22159/ijcpr.2019v11i5.35714

\section{INTRODUCTION}

In 2016 the UK National Health Service (NHS) estimated that 1 million people would be treated through its mental health services by 2021 with 70,000 in the category of children and young people [1]. Stress, depression and anxiety are highly prevalent, with an estimated $20 \%$ of people having symptoms of these diseases [2, 3]. Although, effective therapies are available for depression and anxiety, they are believed to be under-diagnosed and under-treated to avoid stigma [4]. People who are prescribed medication for mental illnesses, require in-depth education and support to understand the side effects and to reduce medication non-adherence [2]. Stress has a significant impact on boththe mental wellbeing and overall health of the individual as the natural response activated in the brain, causes increased neurotransmitter production [5]. Sapolsky (2004) defines stressors as anything in the outside world that un-balances wellbeing and characterises the stress response as attempted corrective action [6]. Mind $\AA$ UK stated that there is no medical definition of stress and health care professionals often disagree over whether stress is the cause of problems or as a result of experiencing them. Also' that stressor may be defined as "situations or events that put pressure on us or our reaction to being placed under pressure" [7].

Selye (1956) explained that stress is defined as a 'reaction of the body to a demand. 'His theory outlined three stages to stress [8]. The first is the alarm stage, where a typical physical reaction is the mobilisation of the body's defence mechanisms; a change in hormone levels with the expansion of the adrenal cortex. The second is the resistance phase where the body tries to adapt to the stressor. The third stage is the exhaustion stage when the second stage coping adaptation becomes ineffective leading to anxiety, headaches, gastrointestinal upset, high blood pressure and depressive symptoms. Financial stress is was described as 'the unpleasant feeling that one is unable to meet financial demands, afford the necessities of life or have sufficient funds to make ends meet' [9]. How an individual reacts to stress is affected by individual characteristics such as age, gender, marital status [10].
Exercising is vital for maintaining mental fitness and is effective in reducing fatigue, improving alertness and enhancing overall cognitive function. It also helps restore depleted energy levels and ability to concentrate. Regular participation in aerobic exercise decreases mental and physical tensions, stabilises mood and improves self-esteem, thereby reducing stress [11]. Support groups may also be important; sharing information with those who have 'been there' is highly effective when coping with symptoms. However, support groups are mainly designed for those that have already been diagnosed with a mental health disorder, for example, anxiety and depression [12]. However a problem in coping, which this investigation showed was that people under stress tend to confide in people close to them rather than people who would have the appropriate knowledge and skill to help [13].

Pharmacists are well positioned within the community to provide primary care and have the background knowledge and training to make them valuable healthcare professionals [14]. They have the most frequent contact with patients, with an estimated 7.3 million patients in the UK receiving regular antidepressants medication [15].

Pharmacists have improved patient's outcomes when compared directly to physicians in areas such as medications management and self-care education [16]. They also participate in health-promotion activities, locally and internationally, on a wide range of health-and medication-related topics.

\section{Aim}

The study aims to explore perceptions in the university local populations about stress, its causes and management.

\section{MATERIALS AND METHODS}

\section{Method and design}

This project aimed to highlight the benefits of pharmacists 'campaigns to reduce stress. Although there is previous research within mental health prevention, none were identified that aligned 
with the aim of this study. The questionnaire used in this study used closed questions with one open-ended question at the end, as it was deemed to be quicker for respondents who are taking part within their short breaks between classes. A questionnaire was used instead of an interview as responses would be anonymous and less stressful to the participants who are currently affected by mental illhealth. Students from the University of Wolverhampton were the target population pool as it was reported in the UK psychiatric Morbidity Survey (2014) that there have been significant increases in anxiety and depression in young people between 16 and $24 \mathrm{y}$ of age [1].

Questionnaire based research provides informative and useful human information to interpret and understand complex situations. Ethics approval was obtained from the School of Pharmacy Ethics Board. Anonymity and confidentiality were discussed with the participants and the ethical approval letter was displayed to assure participants on how their data would be used. An information sheet was provided. The return of a completed questionnaire was considered as the participants' implied consent to participate. The participants' ages, gender and ethnicity were also collected for further analysis similar to the methods of Luborsky and Rubinstein (2011) [17]. To analyse this data, Microsoft Excel ${ }^{\mathrm{TM}}$ software was used.

\section{RESULTS}

More females (64\%) than males (36\%) participated in this study, accordingly data was analysed as percentage rather than counts of frequencies. Similarly, there were more 18 to 24-year old (52\%) than all other age groups (26\% in $25-34$ y-group, $10 \%$ in $35-44 \mathrm{y}$ group, $6 \%$ in $45-54$ y-group and $6 \%$ in the 55 +years-group). Fig. 1 shows the sample ethnicity breakdown.

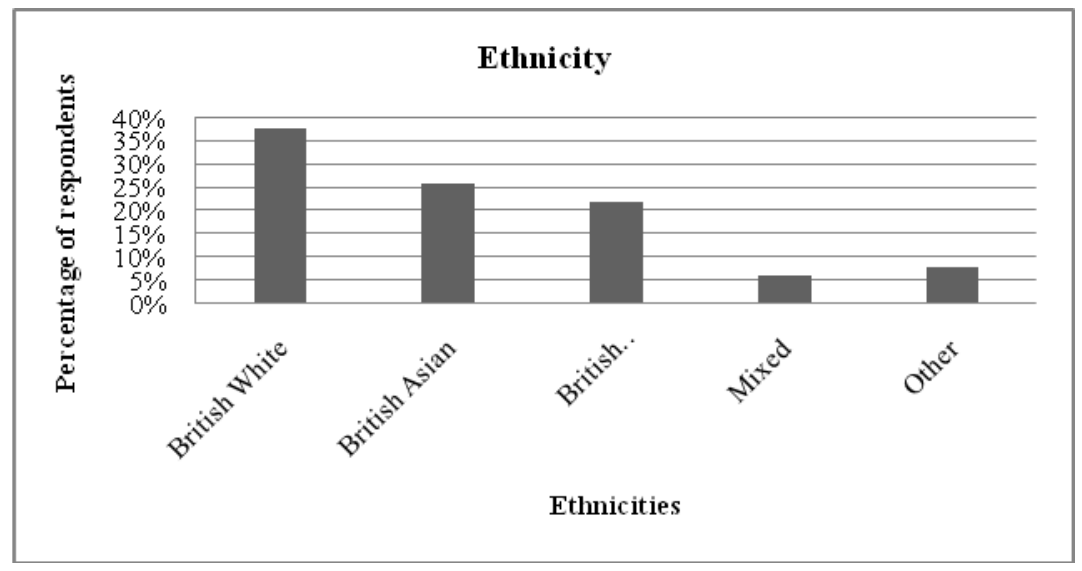

Fig. 1: Participants by ethnicity

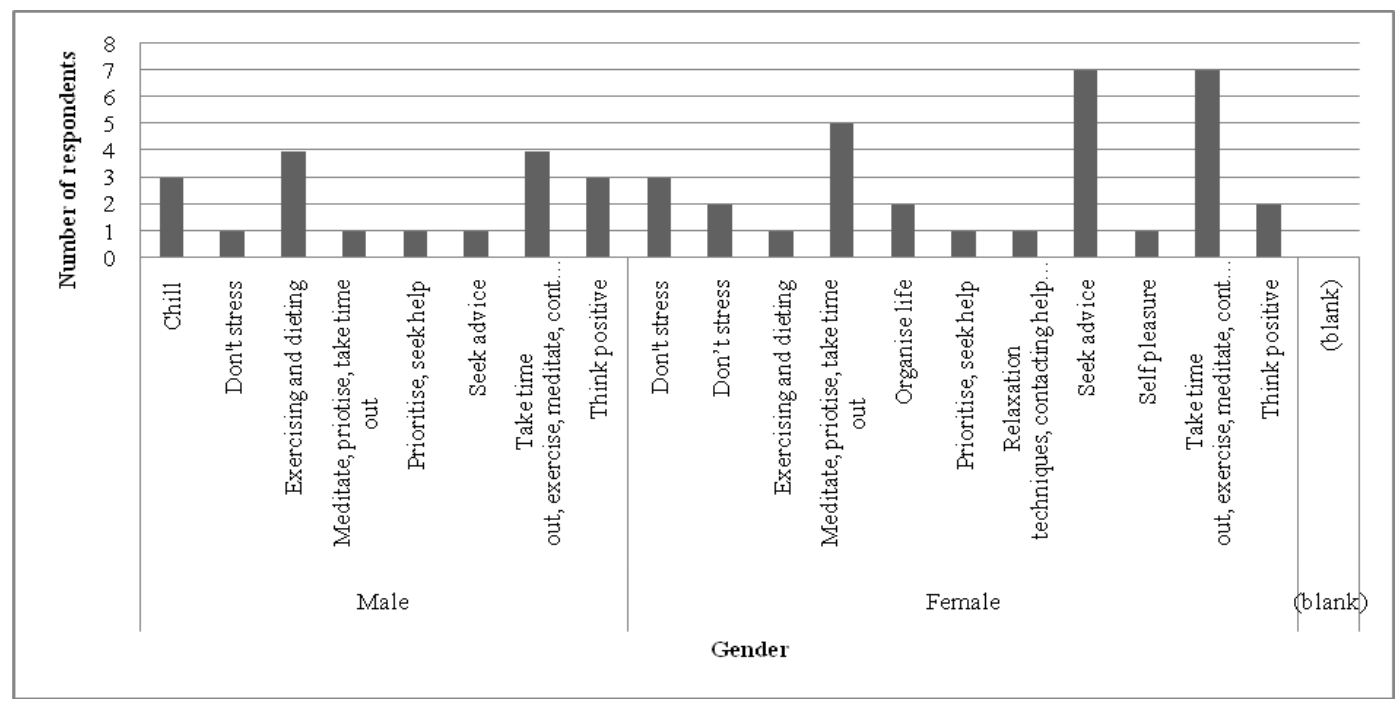

Fig. 2: Graph of gender for question 2

Question 1: Do you think individuals are able to manage stress without professional help?

Of males, $83.3 \%$ agreed that stress can be managed without professional help versus $90 \%$ of females. There were more (96\%) participants from 18-24 y-group in agreement compared to all other groups (96\%,84\%, 80\% and 66\% respectively). The majority of British White $(84 \%, \mathrm{BW})$ agreed stress can be managed without professional help versus $100 \%$ of British Asians (BA), $82 \%$ of Black/Caribbean (BC) and $75 \%$ of the other and mixed ethnicity (ME).
Question 2: What advice would you give to yourself or someone else on how to deal with stress?

Fig. 2 shows the breakdown of responses; the most selected options were: 'take time out' and 'exercise.' One in five (19\%) of all 18-24-year old selected 'exercise and diet', where $31 \%$ of the 25 $34 \mathrm{y}$ olds chose the 'take time out option' and in the 35-44 y old 'thinking positive' was the most selected option at $40 \%$. In the 45 54 age group the 'taking time out 'option was their preferred answer (67\%). Only in the 55+age group was 'seeking advice' the most popular response $(67 \%)$. Thirty two percent of BW chose 
'take time out' and the majority of B Aselected 'do not stress' (31\%). B Cselected most options (meditating, prioritizing and taking time out [36\%] and exercising, contact support whilst taking time out [36\%]).

Question 3: Who do you think a stressed individual should approach first?

The majority of participants selected 'approach friends' (83\% males and $84 \%$ females). When looked at age groups, $88 \%$ of $18-24$ y old, $92 \%$ of $25-34$ y old, $380 \%$ of $35-44$ y old, and $67 \%$ of $45-54$ y old groups selected approach 'friends 'or 'family member' only. This is agreeing with the national statistics that only $36 \%$ of people with mental illness seek professional help or treatment [7].

\section{Question 4: Do you believe medication can help cure stress?}

There were $61 \%$ of males and $69 \%$ of females selected 'No'. From all who responded 'No,' there were $79 \% \mathrm{BW}, 73 \%$ of $\mathrm{BC}, 67 \%$ of $\mathrm{ME}$ and only $46 \%$ of BA.

Question 5: What do you think would be the most helpful to manage stress?

Around half of males and females believed that universities should be educating students about stress (50\% and $56 \%$ respectively) with health care professionals advising about stress coming second in both genders at $33 \%$ and $41 \%$ respectively. However, only $22 \%$ of males and $28 \%$ of females selected 'the community pharmacist should be the point of education.'

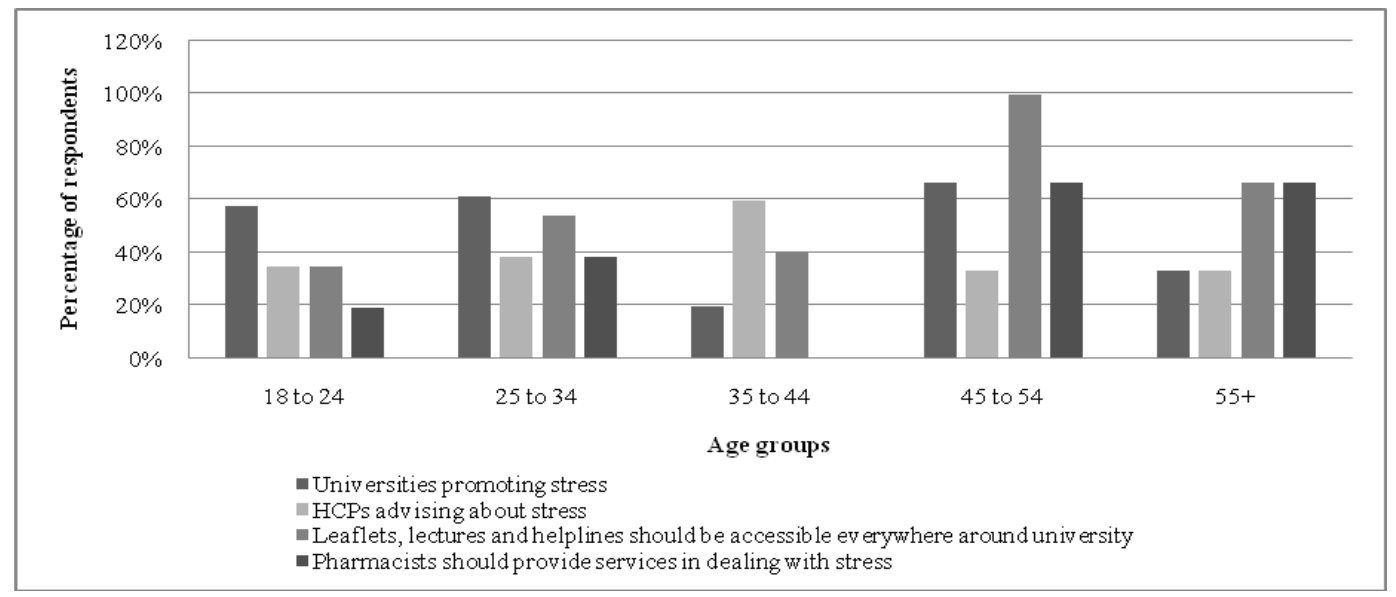

Fig. 3: Graph of age for question 5

\section{Question 6: What does the word stress mean?}

Males believed stress relates to heightened emotions (22\%) and being under pressure $(22 \%)$ similarly to females, choosing heightened emotions (28\%) and being under pressure (28\%). Fig. 4 shows the answers by age groups. Out of all participants $47 \%$ of BW selected 'under pressure', 39\% of BA selected 'worrying', 27\% BC answered 'heightened emotions' and 33\% ME answered 'stress to be panicking'.

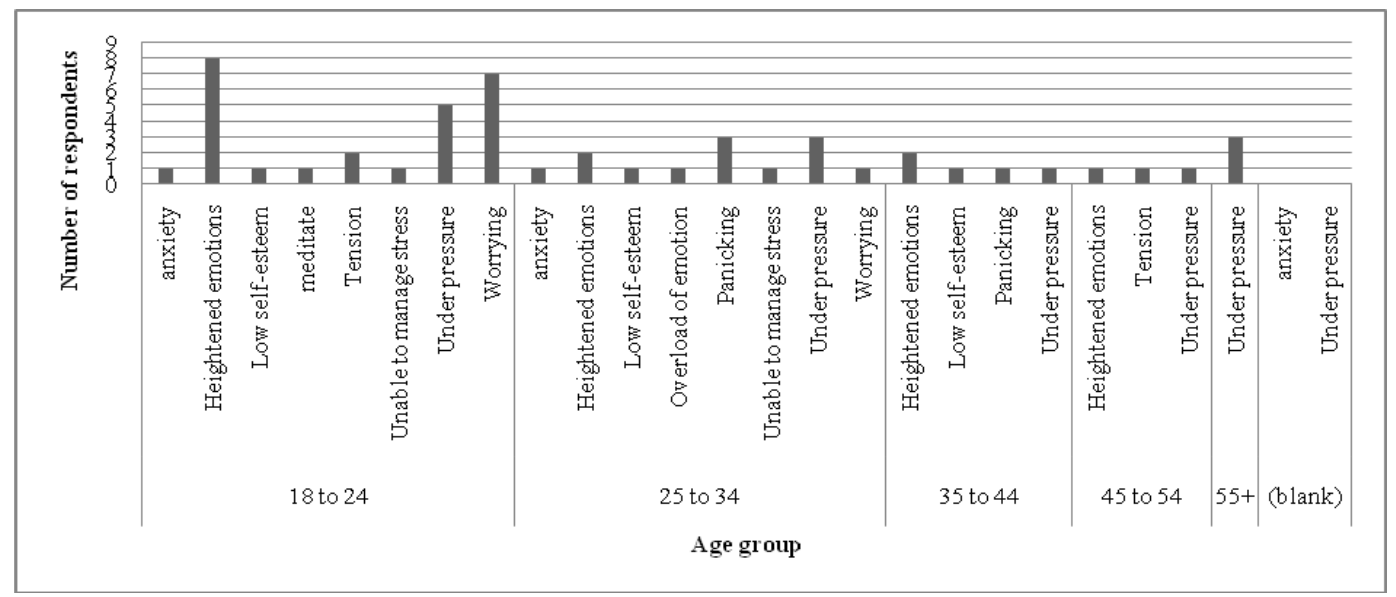

Fig. 4: Graph of age group for question 6

\section{Question 7: What are some of the stress signs and symptoms?}

Males selected insomnia (83\%) as the most common symptoms of stress followed by depressed (72\%). Females' participants chose low energy as sign of stress followed closely by feeling depressed (75\%), (fig. 5).

For this question, from participants in age group 18-24, 77\% answered 'depressed' and 77\% selected low energy and headaches as top symptoms. In the age group 25-34, 92\% selected 'depressed', 'low energy and headaches equally. In the 35-44 age group, $80 \%$ participants selected 'fear, insomnia, chest pain and rapid heartbeat'.

\section{Question 8: What are the TWO biggest stress risk factors?}

Male participants (56\%) selected work and emotional problems as their biggest factor of stress whereas females picked emotional problems (69\%) as top choice.

Responses by age group are illustrated in fig. 6. Majority of BW and BA participants selected emotional problems (74\%, 85\% respectively). BC selected financial obligations (55\%) and emotional problem (55\%) as biggest risks of stress. ME selected work and chose studies as biggest stressors (100\%). 


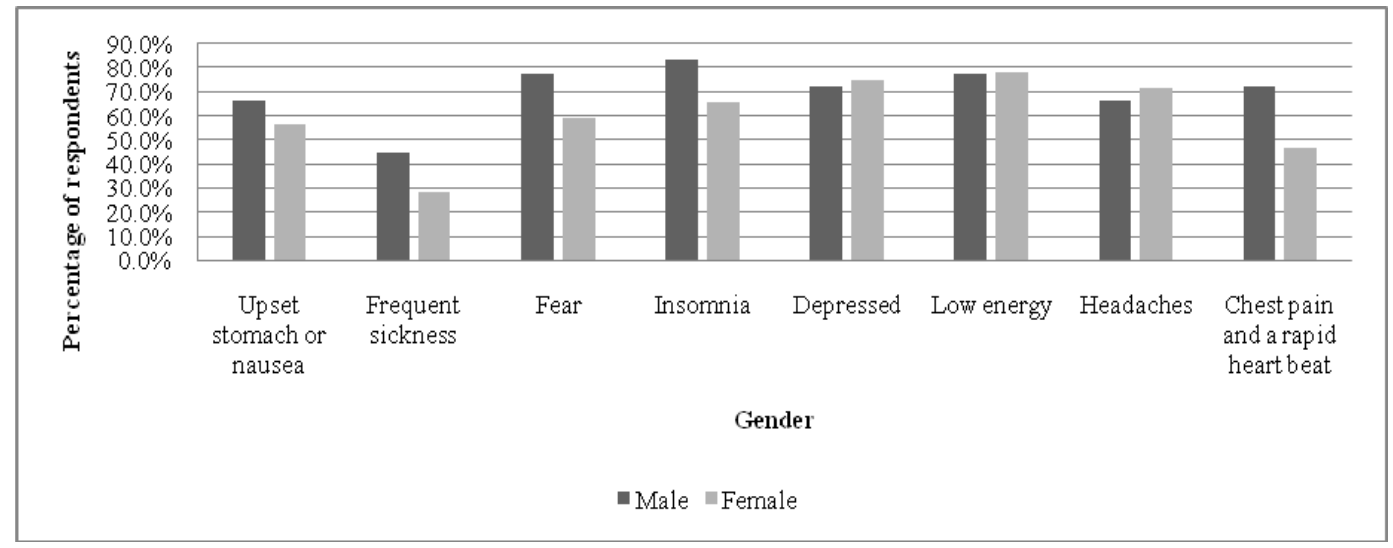

Fig. 5: Graph of gender for question 7

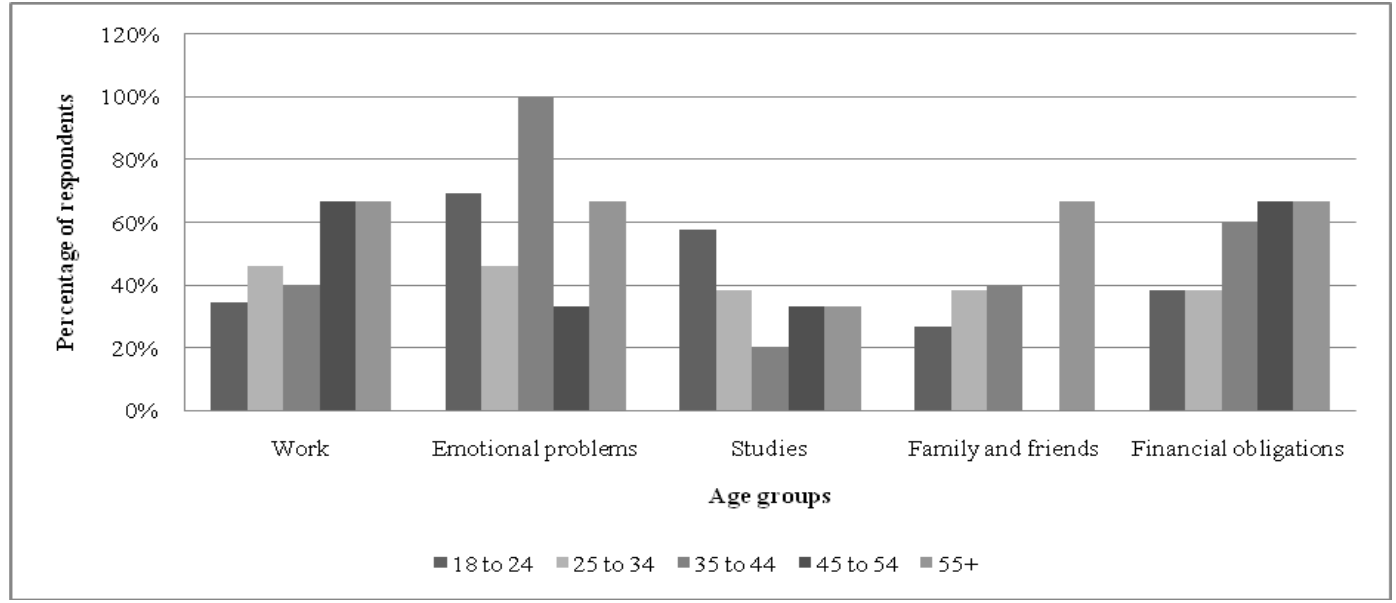

Fig. 6: Graph of age group for question 8

\section{Question 9: Can exercising relieve stress symptoms?}

Both males and females answered selected yes (72\% and $88 \%$ respectively). When analysing the results by age, the majority of all age groups selected yes as the correct answer (77\%, 92\%, 60\% and $100 \%$ for $18-24,25-34,35-44$ and all others). A majority (84\%) of BW participants selected Yes, all BA (100\%), $72 \%$ of BC and $60 \%$ of ME.
Question 10: What are some of the methods you can use to manage with stress?

Males and females selected talking with someone as a good method to deal with stress $(94 \%, 81 \%$ respectively). However, when analysed results by age (fig. 7 and ethnicity (fig. 8) the difference was more significant.

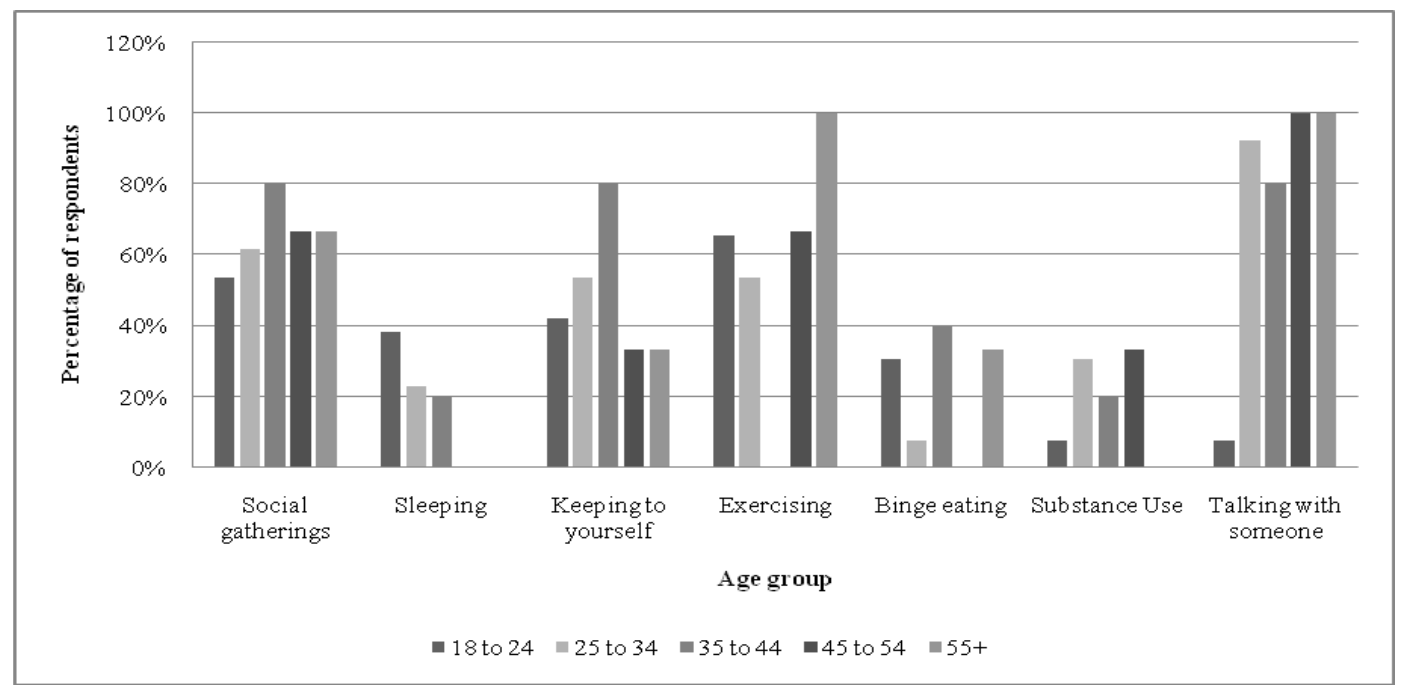

Fig. 7: Graph of age group for question 10 


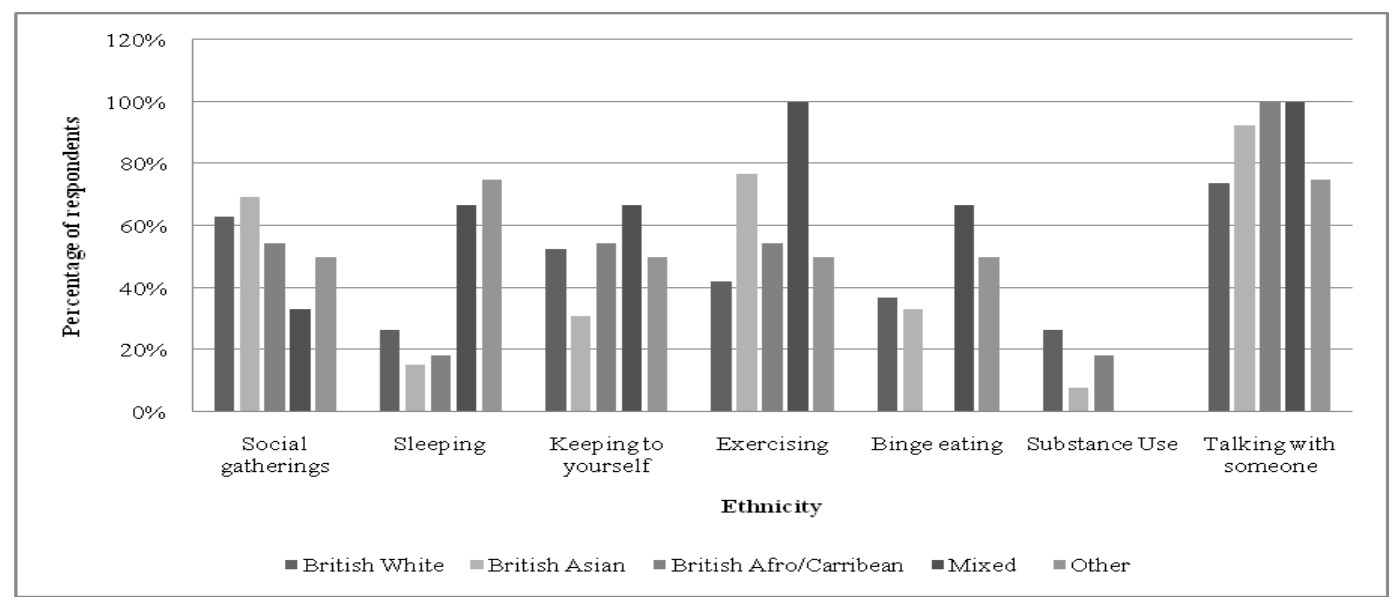

Fig. 8: Graph of ethnicity for question 10

\section{Question 11: Can stress lead to more serious illnesses?}

Almost all participants answered yes (100\% Male, 97\% Female), stress can lead to serious illness.

\section{Question 12: If yes, what can it lead to?}

The top two options were 'stress can lead to health and mental health issues' by males (39\%) and 'depression' by females (38\%). BW and ME participants selected health and mental issues $(27 \%, 67 \%$ respectively), BA and BC selected depression (69\%, 60\% respectively). Analysis by age did not show any significant differences.

\section{Question 13: Does eating healthily affect your mental health?}

Majority of males (94\%) answered yes however, females were lower at $84 \%$.

\section{Question 14: Does smoking or drinking alcohol effect stress levels?}

More male participants selected smoking (78\%) then alcohol $(61.1 \%)$ as second option. Females selected both smoking and alcohol equally (79\%). There were no differences when the result was analysed by age and ethnicity.

Question 15: What is the first-line treatment when dealing with stress?

Male and female participants selected Cognitive Behavioural Therapy (CBT) (67\% and 66\%) followed by complementary therapy (39\% and 41\%). All age groups followed the same pattern with no significant differences between groups (CBT average of $75 \%$ and complementary therapy average of 35\%). British White's chose CBT (63\%) very closely followed by complementary therapy (53\%). Similarly, all ethnic groups followed the same pattern with no significant differences between groups (CBT average of $70 \%$ and complementary therapy average of $65 \%$ ).

Question 16: Which three lifestyle changes do you think can help when dealing with stress?

Male and female participants selected 'being active' as best option (83\% and 84\%).

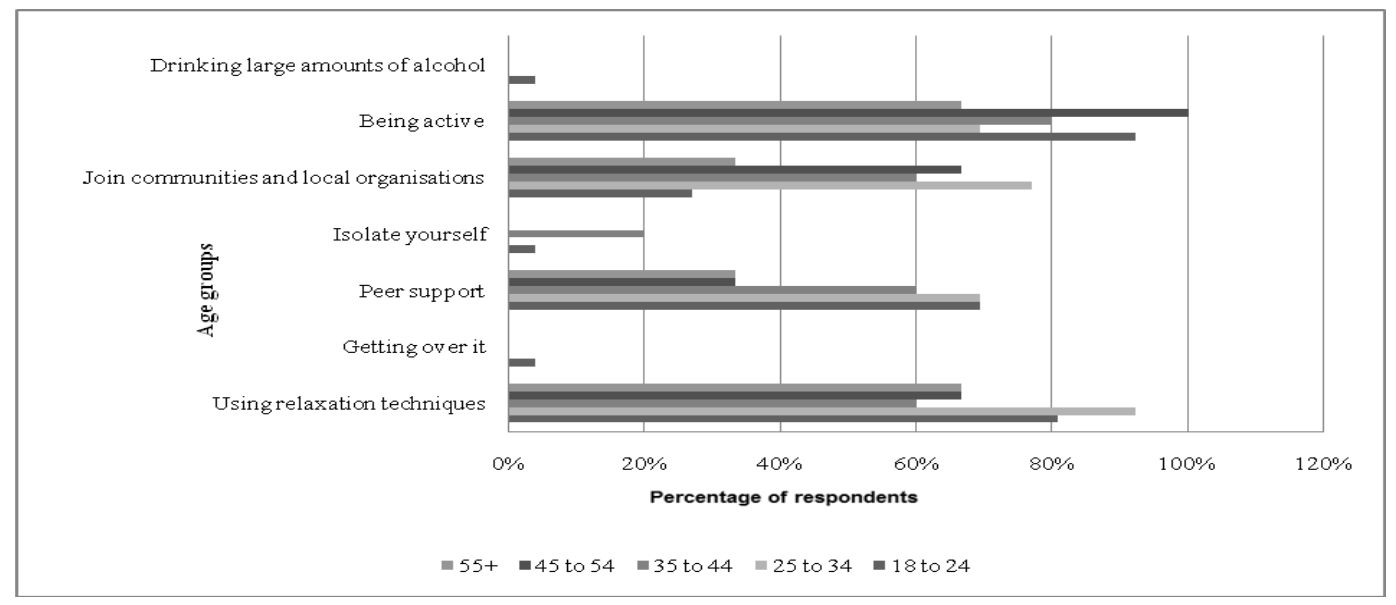

Fig. 10: Graph of age groups for question 16

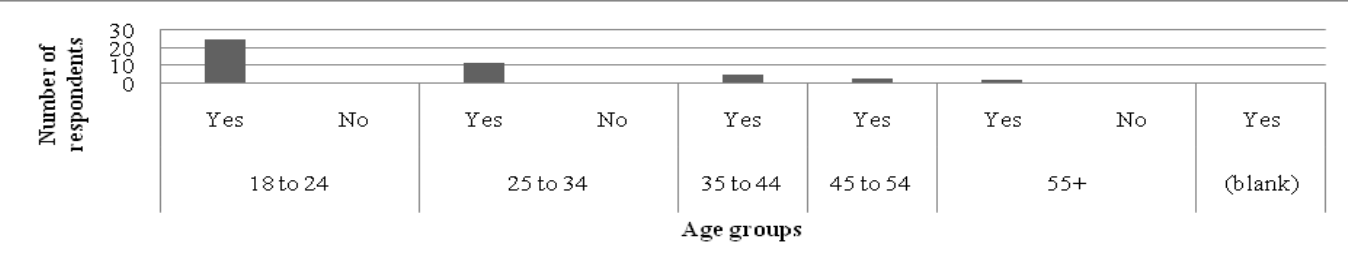

Fig. 11: Graph of age group for question 17 


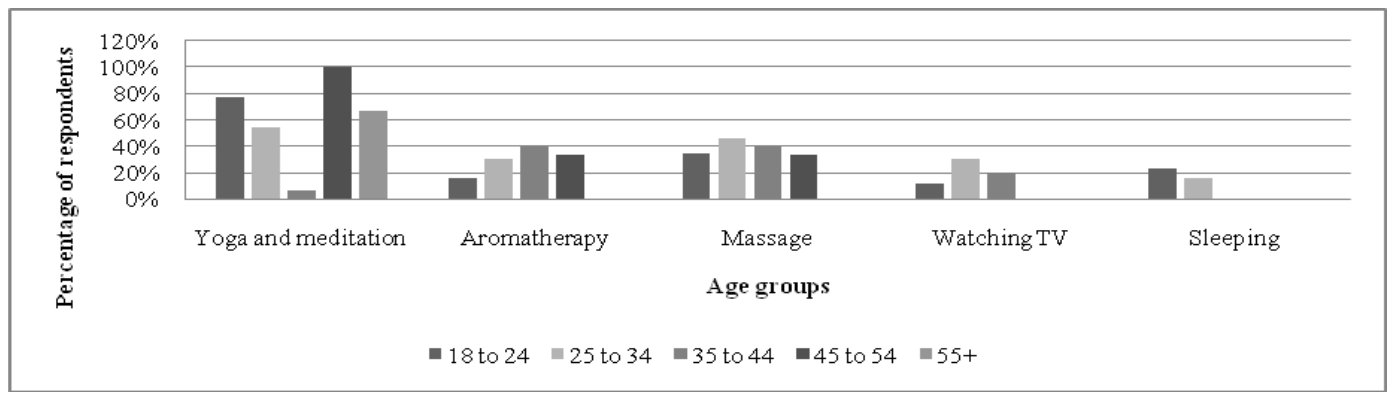

Fig. 12: Graph of age group for question 18

Question 17: Should individuals who are stressed try complementary therapies?

Almost all male and female participants selected complementary therapies should be used (94\% and $94 \%$ ). Age groups analysis is illustrated at fig. 11.

Question 18: If yes, tick which of the following therapies would be the best treatment?

Majority of male and female participants selected yoga and meditation would be the best treatment ( $61 \%$ and $69 \%$ ). Age groups analysis is illustrated at fig. 12 . There were significant differences when the result was analysed by ethnicity. BW, BA and ME selected yoga and meditation $(63 \%, 69 \%$ and $100 \%)$. BC selected yoga and meditation (55\%) followed by massage at $45 \%$.

\section{Question 19: Have you heard about 'Minds'?}

Out of all participants $61 \%$ of males and $65 \%$ of females said yes. There were no significant differences when the result was analysed by age and ethnicity.

Question 20: Have you heard about 'Mental Health First Aid England'?

Most participants selected no (61\% of males and $66 \%$ of females). There were no significant differences when the result was analysed by age and ethnicity.

\section{Question 21: Have you heard about the '3-Minute Saves a Life'?}

Most participants selected no ( $67 \%$ of males and $72 \%$ of females). There were no significant differences when the result was analysed by age and ethnicity.

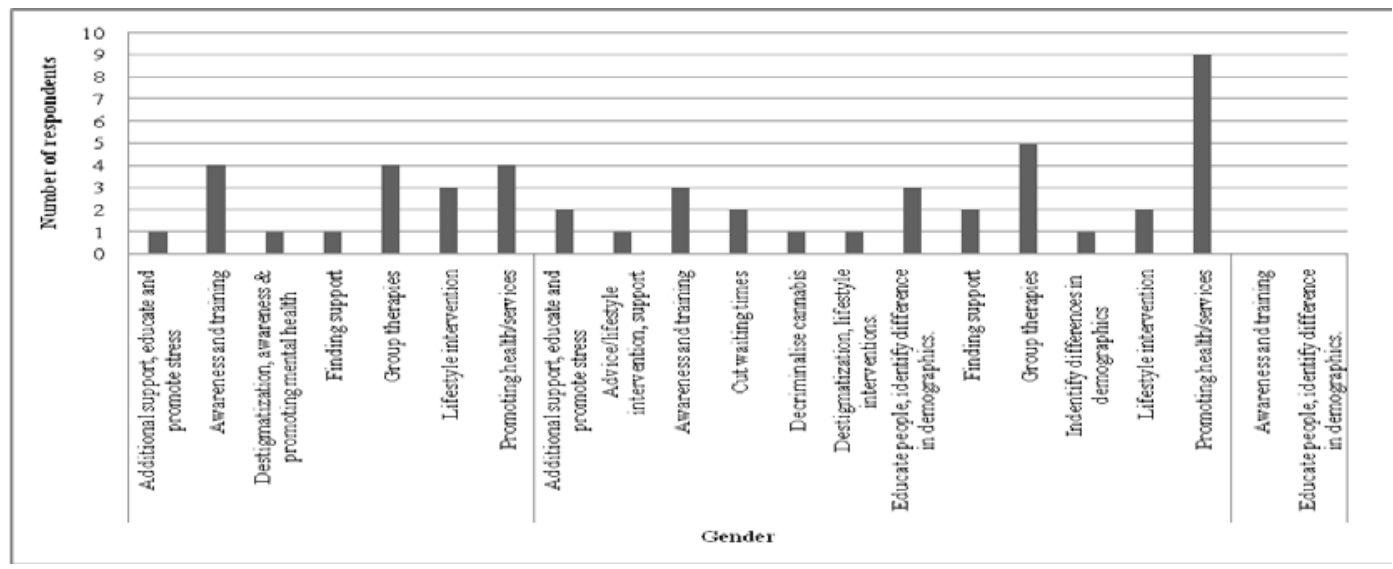

Fig. 13: Graph of gender for question 22

\section{Question 22: State what you believe medical professionals can do to improve the communication of patients with mental health?}

Male participants believed that group therapies (22\%), awareness and training (22\%) alongside promoting health services $(22 \%)$ would help. Females who believe promoting health services is the best option was $28 \%$, (fig. 13). Out of all 18-24 age group participants $23 \%$ selected 'health services', $54 \%$ of $25-34$ age group selected 'group therapies', $80 \%$ of the $35-44$ age group selected 'health services', $67 \%$ of $45-55$ age group selected the 'awareness and training 'option, where $33 \%$ of the 55 +participants selected awareness, training and health services. Out of all participants, BW (32\%), BA (39\%) and ME (33\%) participants selected 'health services' and BC selected group therapies (27\%).

\section{DISCUSSION}

Mental disorder rates are at an all-time high and support at early stages will strengthen the public's abilities in coping and setting future goals. Understanding the thought process and stressors certain demographics undergo can better inform the way health promotion can be designed.

In knowledge-based questions, some participants incorrectly selected insomnia and depression as a symptom of stress instead of being caused by stress, however, the majority of participants understood the symptoms that can arise; low energy, headaches, chest pain and rapid heartbeat. This study found that BC Participants experienced more chronic stress than other groups which agree with the national statistics [2]. The Mental Health Foundation explains that Black and Minority ethnic groups are more likely to be diagnosed with mental health problems as a result of the health system failing to provide service tailored to their needs and cultural differences. Interestingly, participants of the 18-24 age group incorrectly selected symptoms where the 35-44 age group selected all correct symptom of stress which may indicate lack of awareness about stress in young people in the UK. The results from this study displays that participants understand that chronic stress generates long-term changes in the brain leading to mental health disorders [18]. The survey responses indicated that male participants believed 
smoking had a larger effect than alcohol where females thought that the opposite was correct. Only $40 \%$ of the $35-44$ age group believed that smoking has an influence on stress. Only $61.5 \%$ of Asians considered that smoking can affect stress.

The present study sought to determine major factors of stress the participants face. Male participants chose work (55.6\%) and emotional problems $(55.6 \%)$ as their biggest factor of stress whereas females picked emotional problems (68.8\%) as top choice which is similar to Butler (1973) [19]. Combining a job with studies can cause stress. Most students work to help in both living expenses and university fees. The workload from studies combined with a job can be difficult to handle-causing individuals to miss study days, feel down, low energy and burned-out by too many commitments [20]. Working whilst studying can interfere with performance in university; increasing stress. British African/Caribbean (55\%) selected financial obligation as the cause of their stress. Studies show that financial stress can lead to depression, anxiety and suicide $[21,22]$. Students chose studies $(46.8 \%)$ as one of the largest impacts of stress. Underachieving causes students to feel down and lose motivation leading to over thinking and stress. Missing lectures due to jobs causes students frustration and confusion. West Midland residents find the main cause of stress to be work, absence behaviour and intention of quitting the job are related to work stress [23]. In this study it was observed that stressful life events including studies, work, and financial obligation were associated to be the biggest risk factors of stress amongst the participants. Students deal with financial difficulties whilst dealing with assignments and exams to complete.

Participants were questioned on their thoughts on what medical professionals can do to improve the future when dealing with stressed individuals. From analysis of the data, $6.3 \%$ of female participants highlighted 'waiting times to contact healthcare professionals'. The Royal College of Psychiatrists survey concluded in 2005 waiting time for treatment can be up to $13 \mathrm{w}$ [23]. Pharmacists are easy to access; patients would not have to wait until their stress level deteriorates [24]. Pharmacists can help patients directly and work with them in finding appropriate helpin interviews that would approximately take only 5-10 min within the consultation room. One in six of the population are diagnosed with a mental disorder within the U. K. which is growing by the year [2]. Out of all participants, $83 \%$ of male participants and $84 \%$ of female participants were more likely to speak to 'friends' about their stressors and how to deal with it. The results suggest participants may not understand the full extent of the role of pharmacists. Many in society believe pharmacists only dispense prescriptions [24]. Changing this perception will allow the public to confide more in pharmacists and pharmacies to implement stress, mental health services as the prevalence is increasing [25]. Healthy living pharmacy services should increase stress management services to promote and support health and well-being.

\section{LIMITATION}

The age group that completed the questionnaires were mainly 1824-yearsold. There is already little information about the effects of age when it comes to dealing with stress. All questions had options to select from, having one or more open questions would allow participants feedback, however due to the nature of university breaks being short and to enable more students to take part this was not feasible in this study. While the results cannot be generalised to the entire university population, the findings offer valued insight for future studies when promoting stress this study was self-reported which may depict experiences.

\section{CONCLUSION}

There are very few studies examining the effect of health promotion for stress management and early symptoms detection. This research was exploratory, and the findings indicated that further researchis required to reduce the prevalence of stress progressing to mental illness. Stress management should be incorporated into courses to help address and reduce stress amongst students. The student union should co-operate with health organisations such as 'Mind' and 'Mental Health First Aid England' to instil organised well-structured programmes free of charge for students to attend. To improve the role of pharmacist, mental health management should be offered to undergraduate students to enable them to provide quality advice and direct patients to appropriate help. Also, the NHS should incorporate leaflets that are accessible to public about the symptoms of stress and emphasise the importance of healthy eating, physical activity and social interactions as social first line intervention.

\section{AUTHORS CONTRIBUTIONS}

All the author have contributed equally

\section{CONFLICT OF INTERESTS}

\section{Declare none}

\section{REFERENCES}

1. McManus S, Bebbington P, Jenkins R, Brugha T. (eds.). Mental health and wellbeing in England: Adult Psychiatric Morbidity Survey 2014. Leeds: NHS Digital; 2016.

2. Mental Health Statistics. Mental health statistics: the most common mental health problems; 2018. Available from: https://www.mentalhealth.org.uk/statistics/mental-healthstatistics-most-common-mental-health-problems [Last accessed on 24 Apr 2019]

3. MHFA Portal. MHAW18: Top tips for reducing stress in the workplace; 2019.2 Available from: https://mhfaengland.org/mhfa-centre/blog/lisa-fathersstress-workplace. [Last accessed on 24 Apr 2019]

4. Robinson J. Challenging the stigma. Pharm J 2017;299:7907.

5. Hatef B, Mohammadi A, Yaribeygi H, Meftahi G. Intensity and prevalence of source of stress in Iran. Health Res J 2016;1:1-2.

6. Sapolsky R. Social status and health in humans and other animals. Ann Rev Anthropol 2004;33:393-418.

7. Mind.org.uk. Stress | Mind, the mental health charity-help for mental health problems; 2018. Available from: https://www.mind.org.uk/information-support/types-ofmental-health-problems/stress/\#. XLNi-VNKjOQ. [Last accessed on 24 Apr 2019]

8. Selye H. The stress of life. New York, NY, US: McGraw-Hill; 1956.

9. Davis CG, Manter J. The consequences of financial stress for individuals, families, and society; 2018. Available from: https://pfeef.org/research/efd/Consequences-Fin-Stress-forIndividuals-Families-and-Society.pdf. [Last accessed on $24 \mathrm{Apr}$ 2019]

10. Chang K, Lu L. The influence of occupation on stressors and work behaviours. Int J Human Resource Management 2009;20:591-605.

11. Matta C. 3 Ways to relax in the face of stress. Psychiatry Central; 2012. Available from: https://blogs.psychcentral.com/dbt/2012/09/3-ways-torelax-in-the-face-of-stress/. [Last accessed on 11 Mar 2019]

12. Griffiths K. Mental health Internet support groups: just a lot of talk or a valuable intervention? World Psychiatry 2017;16:247-8.

13. Stoica M. Occupational stress management. Management Health 2010;14:7-9.

14. Hughes C, Breault R, Hicks D, Schindel T. Positioning pharmacists' roles in primary health care: a discourse analysis of the compensation plan in Alberta, Canada. BMC Health Services Res 2017; 17:770.

15. Pfeiffer B, Stellingwerff T, Hodgson A, Randell R, Pöttgen K, Res P, et al. Nutritional intake and gastrointestinal problems during competitive endurance events. Med Sci Sports Exercise 2012;44:344-51.

16. Munger M, Feehan M. Community pharmacists' occupational satisfaction and stress: a profession in jeopardy? Response to Rodis and Ulbrich. J Am Pharm Assoc 2014;54:7.

17. Luborsky M, Rubinstein R. Sampling in qualitative research. Res Aging 1995;17:89-113.

18. Nahl D, Bilal D. Information and emotion: the emergent affective paradigm in information behavior research and theory. ASIST Monograph Series. Medford, NJ: Information Today; 2007. 
19. Butler RN, Lewis MI. Aging and mental health: positive psychosocial approaches. Oxford, England: C. V. Mosby; 1973.

20. Scott Clayton J, Macleod MJ. Stress, debt and undergraduate medical student performance. Med Educ 2006;40:584-9.

21. Eisenberg D, Gollust S, Golberstein E, Hefner J. Prevalence and correlates of depression, anxiety, and suicidality among university students. Am J Orthopsychiatry 2007;77:534-42.

22. McPherson G. Choosing an alternative path. Conserv Biol 2012;26:383-4.
23. Robbins SP. Organizational Behaviour, Englewood Cliffs, NJ Prentice-Hall. Royal College of Psychiatrists; 2018

24. O'Brien M. Public perception of pharmacists must change, says pharmacy minister. Pharm J 2009;283:525

25. Stepping forward to 2020/21: the mental health workforce plan for England. Available from: https://www.hee.nhs.uk/ sites/default/files/documents/Stepping\%20forward\%20to\%2 0202021\%20-\%20The\%20mental\%20health\%20workforce\% 20 plan\%20for\%20england.pdf. [Last accessed on 11 Mar 2019]. 